\title{
Study of Some Immunological Markers of People with Parasitic Infestation and their Relationship to Colorectal Cancer
}

\author{
Ali Slwmee. Serhan Al-halaly ${ }^{1}$, Habeeb Waseel Kadhum Shubber ${ }^{2}$ \\ ${ }^{1}$ Research, ${ }^{2}$ Assit. Prof., University of Al-Qadisiyah/College of Science/Department of Biology, Iraq
}

\begin{abstract}
The aims of this study to find the link between each of the parasites(E. histolytic and Giardiasis) infection and intestinal cancer, This study contain 4 groups :- Group (G1) People with cancer and diarrhea due to the parasite (42) Group (G2) People with cancer and diarrhea without parasites (8) Group (G3) People with diarrhea and parasites (24) and Group (G4) Control (30), blood samples were collected from patients suffering from diarrhea and parasite infection of both types, as well as cancer, Elisa kits were used in our study the proteins (mucin 2, TFF3, CALP) level were measure by using Elisa kit that provided from the China Origin Company Elabscience. The results of the current immunological study showed the level of serum (mucin 2, TFF3, CALP) among the study groups, where the levels of mucin 2 values were (14305.00), (10595.00),(13145.00) and (9350.00)in group (1), and group (2), group (3) and group (4) respectively, and the level of serum values (TFF3)(43.15),(11.90),(29.65) and (8.60)with the same sequence of groups above, and the level of serum values CALP(16320.00),(11220.00),(15275.00) and(8690.00)with the same sequence of groups above as well. The results of the statistical analysis showed that there is a significant difference between the study groups below the probability level $(\mathrm{P}<0.001)$. (mucin 2, TFF3, CALP) with both (carcinogenic parasite) and (parasitic infestation only) and (carcinogenic infection) with different high levels compared to other groups.
\end{abstract}

Our study was concluded there was relationship between E. histolytic and Giardia lamblia infection and intestinal cancer .

Keywords: Colorectal cancer, mucin 2, TFF3, CALP.

\section{Introduction}

Cancer is a group of diseases involving abnormal cell growth with the potential to invade or spread to other parts of the body ${ }^{(1)}$. These contrast with benign tumors, which do not spread ${ }^{(2)}$. Possible signs and symptoms include a lump, abnormal bleeding, prolonged cough, unexplained weight loss, and a change in bowel movements, While these symptoms may indicate cancer, they can also have other causes, Over 100 types of cancers affect humans ${ }^{(3)}$. Intestinal parasites are one of the most serious health problems in developing countries, especially in tropical and subtropical regions ${ }^{(4)}$. Parasites are a serious public health threat being living organisms that consume their food and other requirements from a host. Medicinal parasites are classified into three main groups: protozoa and helminthes (and some arthropods) ${ }^{(5)}$. This study aims to find out the link between each of the parasites $(E$. histolytic and Giardiasis) infection that causes diarrhea and cancer through some vital indicators that were taken in this study.

\section{Materials and Method}

\section{Experimental design:}

This study contain from 4 groups:

- Diarrhea Parasite and cancer group (G1).

- Diarrhea and cancer without parasites group (G2).

- Diarrhea and Parasite group (G3).

- Control group (G4).

Samples collection (Stool and Blood): Stool samples were collected from patients with diarrhea and parasite infections, as well as cancer. And blood 
was collected from the same patients in addition to the control group.

Immunological Examination: Serum separation -: Blood samples (EDTA-free) were left for 20 minutes at room temperature until the blood clotted, then the samples were centrifuged using a centrifuge at 3000 rpm for 10 minutes, separating the serum from other blood components using a pipette. Min and put into $10 \mathrm{~mL}$ tube. Then the tubes containing the serum were preserved at a degree of $\left(-20^{\circ} \mathrm{C}\right)$ until immunological tests were performed on them. (A) Immunological detection of vital signs: The serum separated by this test is used to estimate the ratio of mucin proteins, trifoyl protein, and calprotectin, using a technique called Enzyme-linked immunoassay (ELISA) technology. immunology assay according to the manufacturer's instructions (Elabscience).

Statistical analysis: - All results in this study were subjected to statistical analysis to find out the significant differences of the studied variables using the tests (kruskalwallis test) at a probability level $(p<0.001),{ }^{(6)}$.

Kits: Elisa kits in this study were obtained from the China Origin Company Elabscience.

\section{Results}

Mucin (ng/ml): The results of the study showed that the concentration of mucin 2, the serum levels were 14305.00 (3912.50), 10595.00 (387.50), 13145.00 (175.00) and 9350.00 (90.00) in group of cancer with parasite, cancer with no parasite group, diarrhea and parasite group and healthy control group, respectively. There was highly significant variation in mucin 2 level among study groups $(p<0.001)$. The level was highest in group of cancer and parasite followed by diarrhea parasite group, then by cancer no parasite group and finally by healthy control group, table(1)(4) and figure(1). Thus both cancer and parasite infestation are associated with an increase in the serum level of mucin 2 .

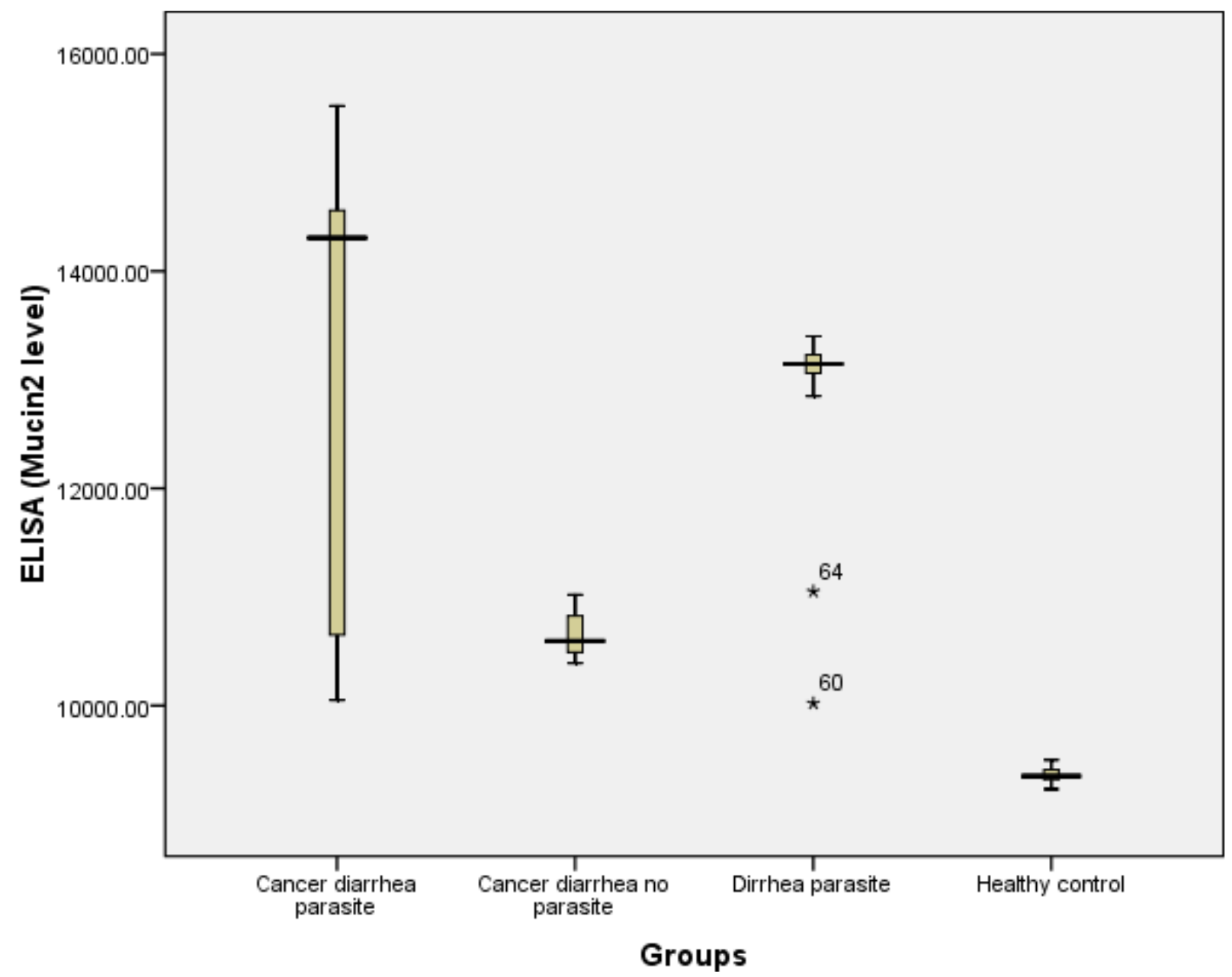

Fig (1): Box plot shows the average level of mucin serum 2 in study totals. 
Table (1): Measure and Compare Serum Level (Mucin 2) between study groups.

\begin{tabular}{|l|c|c|c|c|c|c|}
\hline Characteristic & $\begin{array}{c}\text { Cancer diarrhea } \\
\text { parasite }\end{array}$ & $\begin{array}{c}\text { Cancer diarrhea no } \\
\text { parasite }\end{array}$ & Diarrhea Parasite & Healthy Control & p \\
\hline \multicolumn{7}{|c|}{ Mucin 2 } \\
\hline Median (IQR) & $14305.00(3912.50)$ & $10595.00(387.50)$ & $13145.00(175.00)$ & $9350.00(90.00)$ & $<0.001 \mathrm{~K}$ \\
\hline Range & $10000.00-15500.00$ & $10400.00-11000.00$ & $10000.00-13400.00$ & $9230.00-9500.00$ & HS \\
\hline
\end{tabular}

IQR: inter-quartile range; K: Kruskal Wallis test; HS: highly significant at $p \leq 0.01$

TFF3 (ng/ml): The results of the study showed that the concentration of TFF3 TFF3, the serum levels were 43.15 (37.90), $11.90(0.65), 29.65(2.45)$ and 8.60 (0.70) in group of cancer with parasite, cancer with no parasite group, diarrhea and parasite group and healthy control group, respectively. There was highly significant variation in TFF3 level among study groups $(p<0.001)$.
The level was highest in group of cancer and parasite followed by diarrhea parasite group, then by cancer no parasite group and finally by healthy control group, table (2)(4) and figure (2). Thus both cancer and parasite infestation are associated with an increase in the serum level of TFF3.

Table (2): Measure and Compare Serum Level (TFF3) between study groups.

\begin{tabular}{|l|c|c|c|c|c|}
\hline Characteristic & $\begin{array}{c}\text { Cancer diarrhea } \\
\text { parasite }\end{array}$ & $\begin{array}{c}\text { Cancer diarrhea no } \\
\text { parasite }\end{array}$ & Diarrhea Parasite & Healthy control & p \\
\hline \multicolumn{7}{|c|}{ TFF 3 } \\
\hline Median (IQR) & $43.15(37.90)$ & $11.90(0.65)$ & $29.65(2.45)$ & $8.60(0.70)$ & $<0.001 \mathrm{~K}$ \\
$\mathrm{HS}$ & $7.50-9.50$ & $24.10-33.30$ & $1.00-12.20$ & $2.50-59.50$ & 11.02 \\
\hline
\end{tabular}

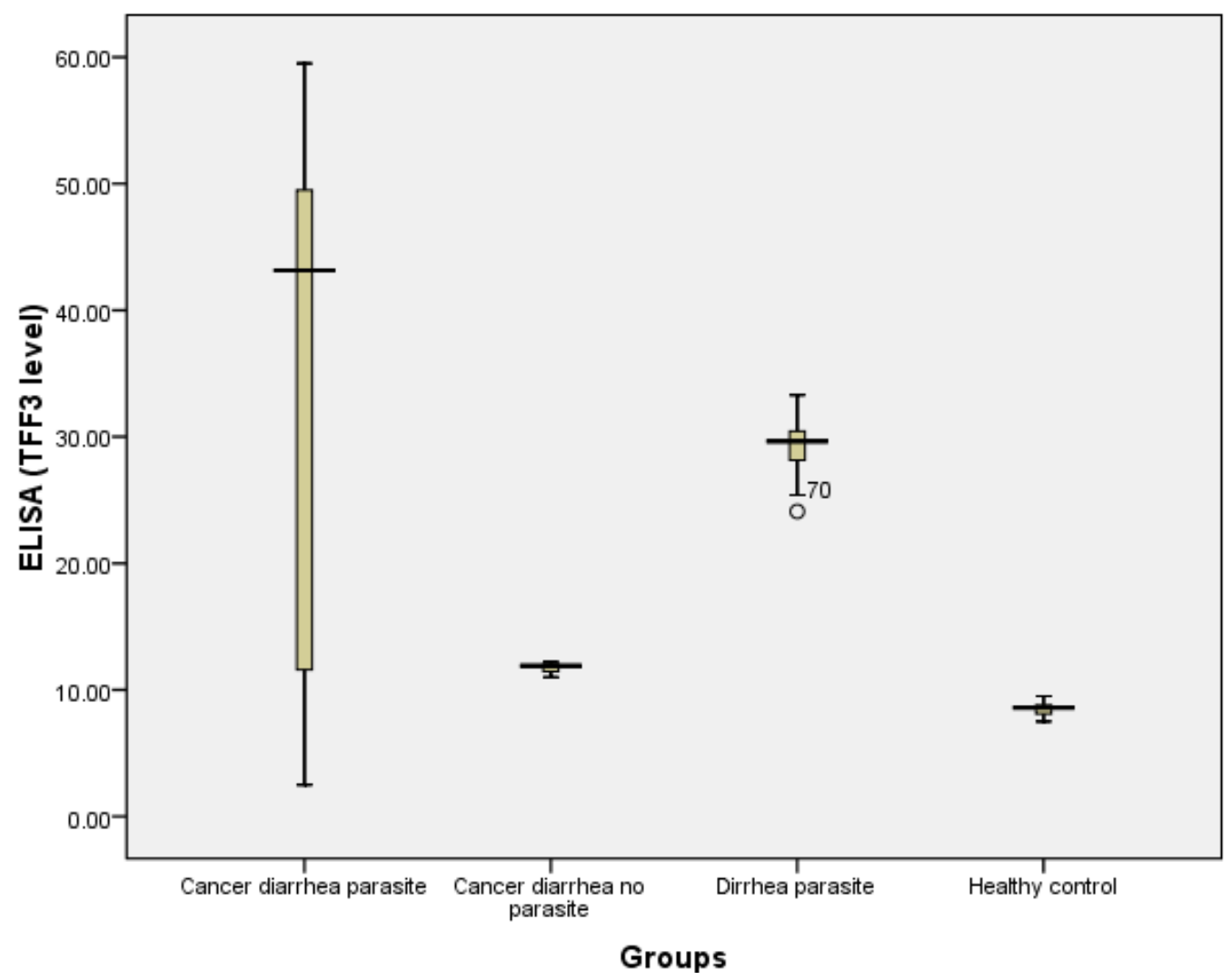

Fig (2): Box plot shows the average level of TFF3 serum in study totals. 
CALP ng/ml: The results of the study showed that the concentration of CALP, the serum levels were 16320.00 (5342.50), $11220.00 \quad$ (332.50), 15275.00 (240.00) and 8690.00 (170.00) in group of cancer with parasite, cancer with no parasite group, diarrhea and parasite group and healthy control group, respectively. There was highly significant variation in CALP level among study groups $(p<0.001)$. The level was highest in group of cancer and parasite followed by diarrhea parasite group, then by cancer no parasite group and finally by healthy control group, table (3)(4) and figure(3). Thus both cancer and parasite infestation are associated with an increase in the serum level of CALP.

Table(3): Measuring and comparing the level of serum (CALP) among study totals.

\begin{tabular}{|c|c|c|c|c|c|}
\hline Characteristic & $\begin{array}{c}\text { Cancer diarrhea } \\
\text { parasite }\end{array}$ & $\begin{array}{c}\text { Cancer diarrhea no } \\
\text { parasite }\end{array}$ & Diarrhea Parasite & Healthy control & $\mathbf{p}$ \\
\hline \multicolumn{6}{|c|}{ CALP } \\
\hline Median (IQR) & $16320.00(5342.50)$ & $11220.00(332.50)$ & $15275.00(240.00)$ & $8690.00(170.00)$ & \multirow{2}{*}{$\begin{array}{c}<0.001 \mathrm{~K} \\
\mathrm{HS}\end{array}$} \\
\hline Range & $11000.00-16900.00$ & $11000.00-12000.00$ & $1570.00-15700.00$ & $8490.00-8850.00$ & \\
\hline
\end{tabular}

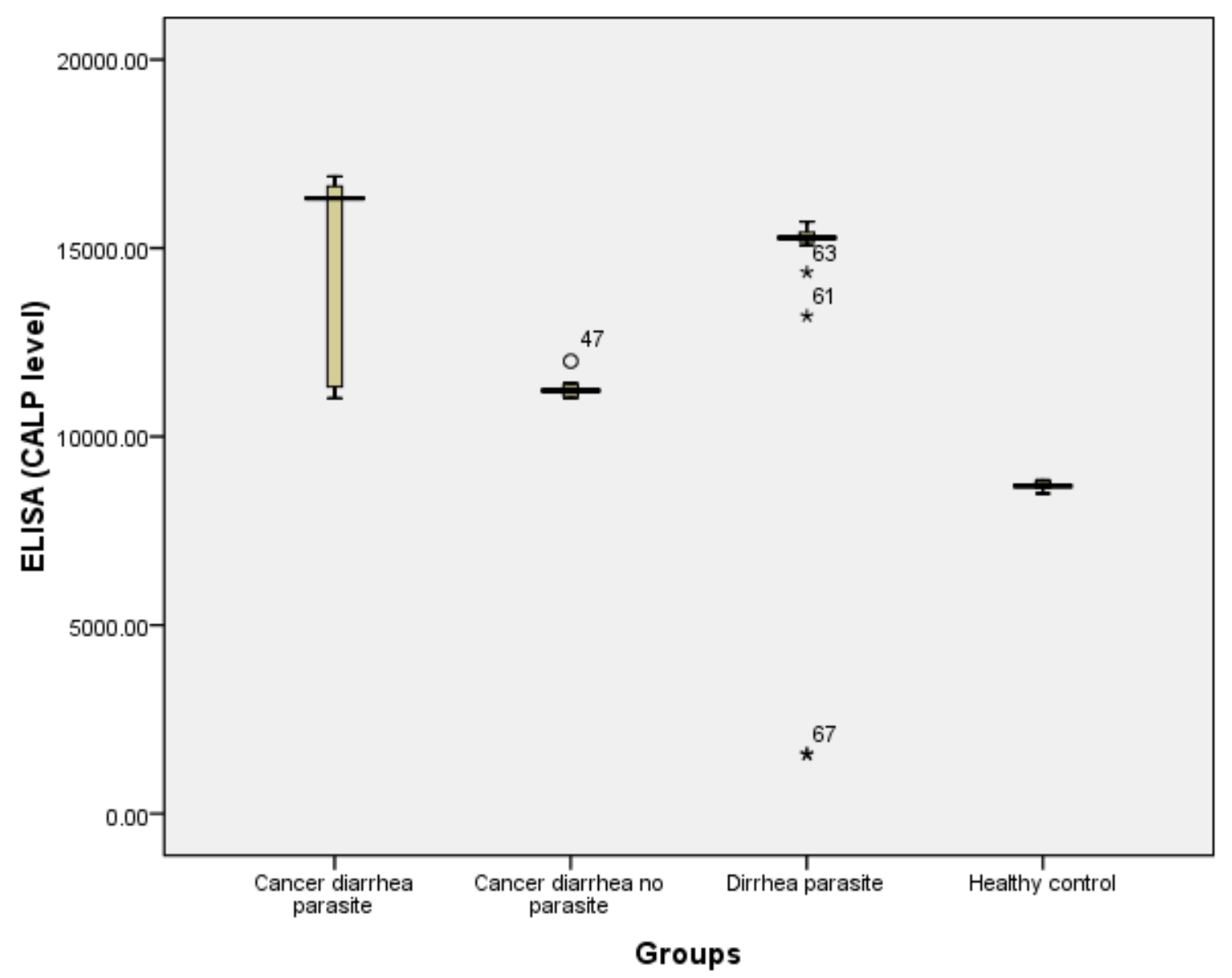

Fig (3): Box plot shows the average level of CALP serum in study totals.

Table (4): Concentration of mucin, TFF3 and CAPL in patients with cancer, parasites and diarrhea.

\begin{tabular}{|l|c|c|c|c|c|}
\hline Characteristic & $\begin{array}{c}\text { Cancer diarrhea } \\
\text { parasite }\end{array}$ & $\begin{array}{c}\text { Cancer diarrhea no } \\
\text { parasite }\end{array}$ & Diarrhea parasite & Healthy control & Pvalo \\
\hline Mucin 2 & $14305.00(3912.50)$ & $10595.00(387.50)$ & $13145.00(175.00)$ & $9350.00(90.00)$ & $<0.001 \mathrm{~K}$ \\
\hline Median (IQR) & $10000.00-15500.00$ & $10400.00-11000.00$ & $10000.00-13400.00$ & $9230.00-9500.00$ & HS \\
\hline Range
\end{tabular}




\begin{tabular}{|l|c|c|c|c|c|}
\hline Characteristic & $\begin{array}{c}\text { Cancer diarrhea } \\
\text { parasite }\end{array}$ & $\begin{array}{c}\text { Cancer diarrhea no } \\
\text { parasite }\end{array}$ & Diarrhea parasite & Healthy control & Pvalo \\
\hline TFF 3 & $43.15(37.90)$ & $11.90(0.65)$ & $29.65(2.45)$ & $8.60(0.70)$ & \multirow{2}{*}{$\begin{array}{c}<0.001 \mathrm{~K} \\
\text { HS }\end{array}$} \\
\hline Median (IQR) & $2.50-59.50$ & $11.00-12.20$ & $24.10-33.30$ & $7.50-9.50$ & \\
\hline Range & $16320.00(5342.50)$ & $11220.00(332.50)$ & $15275.00(240.00)$ & $8690.00(170.00)$ & $<0.001 \mathrm{~K}$ \\
\cline { 1 - 4 } CALP & $11000.00-16900.00$ & $11000.00-12000.00$ & $1570.00-15700.00$ & $8490.00-8850.00$ & HS \\
\hline Median (IQR)
\end{tabular}

\section{Discussion}

The results of the study showed a significant increase in the concentration of TFF3 protein in the serum in patients with Parasites and cancer with diarrhea compared to the group of uninfected people and also a significant increase in the group of infected parasite. The reason for the increased concentration of TFF3 in the person with the parasite is its important role in protecting and repairing the mucous layer of the gastrointestinal tract and into cell migration, usually TFF3 increases when the gastrointestinal tract is damaged and in the case of cancer ${ }^{(7)}$. The anomalous expression of trivoyl protein is associated with gastroenteritis and precancerous tumors ${ }^{(8)}$. The results of the current study are consistent with what it $\operatorname{did}^{(9)}$ where the concentration of TFF3 in serum for people with Giardia lamblia parasite increases and the reason is due to the important role of TFF3 in protecting the mucosa and also agrees with the study of ${ }^{(10)}$.

The results of the current study showed a significant increase in the level of Mucinemyocin in the serum in patients with the parasite when compared with the healthy control group. Mucine is considered the type of MUC2 is the main mucous material secreted in the gut. The reason for the high level of mucin in patients with intestinal parasites is due to the important role that myosin plays in protecting the epithelial layer of the intestinal cavity and also works as a barrier to prevent penetration of germs and parasites into the intestinal wall when eating contaminated food and water Parasiteshosts the mucous layer of the intestine in which colonies are present ${ }^{(11)}$ The presence of bacteria in the mucous layer of the intestine stimulates the immune response of the digestive system and enhances its health ${ }^{(12)}$ when invading and colonizing the parasite of the mucous layer of the intestine It stimulates cystic cells in the intestinal cavity from mucus secretion and this reason leads to increased mucus secretion ${ }^{(13)}$ as a fungal defensive state of the gastrointestinal surface layer of the intestine ${ }^{(14)}$. The parasite has a virulence factor that, upon infection, can Stimulating excessive mucus secretion in the intestine and consequently the storage of myosin, which enables it to adhere to the outer mucous layer of the intestine Myosin plays a protective role through the continuous regeneration of cystic cells and is excreted in the intestinal cavity and does an important job in capturing pathogenic and coexisting parasites and parasites, myosin eventually flows to remove these microorganisms during defecation. ${ }^{(15)}$ The current study is consistent with the study of ${ }^{(16)}$ Also with the study of ${ }^{(17)}$ that showed a high level of MUC2 expression after exposure to the parasite of Giardia lamblia also consistent with the study of ${ }^{(18)}$ that showed a high level of myosin concentration in parasitic infections and agreed with ${ }^{(19)}$ that confirm the high level of myosin in people People with the parasite Giardia lamblia, who adopted the reason for the increase to the pathological physiological response of the parasite Giardia, which develops disease and diarrhea and works to disrupt the mucous layer of the intestine and impede the absorption process.

The present study found an increase in the serum level of calcprotectin in patients with the parasite compared with the control group. Also, there is a slight increase in the serum level of CALP in favor of the infected group compared with the group of infected. This increase may be due to differences in Statistics, sample size and working method can be an increase in the serum level of calcipectin due to intestinal parasites infection. Parasitic infections have a strong effect on the health of the digestive system, especially when the parasite is invasive like E. histolytica. This parasite invades the mucous membrane of the intestine and reaches To the epithelial layer which leads to the formation of calculus ulcers ${ }^{(20)}$ upon parasitic infection, white blood cells multiply and calbrotectin is released, 
which activates the action of neutrophils in the intestinal lining, as it participates in the binding and adhesion of white blood cells to the intestinal lining, The effect of infection with the parasite on the blood level in general, especially white blood cells, where the percentage of hemoglobin is low in a person. Injured patients, and this decrease in the percentage of hemoglobin in the blood can be explained by the persistent diarrhea that affects the necessary elements such as iron, copper, and zinc $^{(21)}$. Fecal calcprotectin (CF) is considered a vital indicator for the diagnosis of IBD but it is not accurate in the diagnosis, The calcipectin protein is profuse in the leukocytes of neutrophils as it is found in the epithelial cells of the intestine and in the monocytes and monocytes, and the level of calcipectin in the feces is proportional to the level of neutrophil in the gut ${ }^{(22)}$. Mucous membranes increase the liberation of calcipectin and can be found in serum and other body fluids as a clinical inflammatory indication ${ }^{(23)}$. It is due to an increase in white blood cells as an immune response against infection.

\section{Conclusion}

Our study was concluded there was relationship between E. histolytic and Giardia lamblia infectionand colon rectal cancer.

Correlation of elevated serum value of mucin 2, TFF3 and CALP with carcinogenicity, parasite infection and co-infection (parasite with cancer) compared with other indicators.

\section{Ethical Clearance: Nil}

\section{Source of Funding: self}

\section{Conflict of Interest: Nil}

\section{References}

1. Anand P, Kunnumakkara AB, Sundaram C, Harikumar KB, Tharakan ST, Lai OS, Sung B, Aggarwal. "Cancer is a preventable disease that requires major lifestyle changes". Pharmaceutical Research. BB (September 2008)25 (9): 2097-116.

2. National Cancer Institute.”Defining Cancer". 17 September 2007. Retrieved 28 March 2018.

3. World Health Organization."Cancer" 12 September 2018. Retrieved 19 December 2018.

4. Bmal-waaly, A. L. I., Shubber, H. W. K., \& Mohammad, M. K. "Prevalence and Pattern of Intestinal Parasites in Children in Al-Diwaniyah
City", Middle Iraq2019.

5. Dawit, A., Ephrem, K., Nagesh, S., Solomon, G. and Fetene, D. "Medical Parasitology Handbook". Jimma University. Ethiopia Public Health Initiative. (2006).

6. Lee, H. S., Jeon, S. W., Nomura, S., Seto, Y., Kwon, Y. H., Nam, S. Y., Ishibashi, Y., Ohtsu, H., Ohmoto, Y., \& Yang, H. M. "Screening Biomarker as an Alternative to Endoscopy for the Detection of Early Gastric Cancer": The Combination of Serum Trefoil Factor Family 3 and Pepsinogen. Gastroenterology research and practice, 2018, 1024074.

7. Kjellev S, Nexo E, Thim L, Poulsen SS." Systemically administered trefoil factors are secreted into the gastric lumen and increase the viscosity of gastric contents". Br J Pharmacol2006;149:92-9.

8. Ting-yiDu; Hui-ming Luo; Hai-chun Qin; Fang Wang; Qing Wang; Yang Xiang Yun Zhang. "Circulating Serum Trefoil Factor 3 (TFF3) Is Dramatically Increased in Chronic Kidney Disease". (2013).

9. Toma Rasha S. and AL-Hadraawy S. K ."Trefoil factor3 (TFF3), Calprotectin (CALP) and (SIgA) as immunological markers in Patients infected with Giardia lamblia Parasite pharm". Sci. and Res. Vol. .(2018) 10(9), 2221-2224.

10. Susumu and others Aikou; Yasukazu Ohmoto; Toshiaki Gunji,NobuyukiMatsuhashi, Hiroshi Ohtsu,Hirona Miura,Kensuke Kubota, Yukinori Yamagata, YasuyukiSeto, Atsushi Nakajima, James R Goldenring, Michio Kaminishi,Sachiyo Nomura. "Tests for Serum Levels of Trefoil Factor Family Proteins Can Improve Gastric Cancer Screening Gastroenterology”. Sep; (2011)141(3): 837-845. e7.

11. Bergstrom KS,Morampudi V, Chan JM,Bhinder G, Lau J, Yang H . "Goblet Cell Derived RELM-beta Recruits CD4+ T Cells during Infectious Colitis to Promote Protective Intestinal Epithelial Cell Proliferation”. PLoSPathog. 2015; 11(8):e1005108.

12. Marchesi JR, Adams DH, Fava F, Hermes GD a, Hirschfield GM, Hold G. "The gut microbiota and host health": a new clinical frontier. Gut. 2015; 0: $1-10$.

13. Chadee K, Keller K, Forstner J, Innes DJ, Ravdin JI." Mucin and nonmucin secretagogue activity of Entamoeba histolytica and cholera toxin in rat 
colon". Gastroenterology. 1991; 100: 986-997. PMID: 2001836.

14. Verma AK, Verma R, Ahuja V, Paul J.” Realtime analysis of gut flora in Entamoeba histolytica infected patients of Northern India". BMC Microbioogy. 2012;12.

15. Belley A, Keller K, Grove J, Chadee K. "Interaction of LS174T human colon cancer cell mucins with Entamoeba histolytica: An in vitro model for colonic disease". Gastroenterology. 1996; 111(6):1484-1492.

16. Manko A, Motta J-P, Cotton JA,Feener T, Oyeyemi A, Vallance BA. "Giardia co-infection promotes the secretion of antimicrobial peptides beta-defensin 2 and trefoil factor 3 and attenuates attaching and effacing bacteria-induced intestinal disease". University of Calgary PLoSONE(2017) 12(6).

17. Amat CB, Motta JP, Fekete E, Moreau F, Chadee K,Buret AG ." Cysteine Protease-Dependent Mucous Disruptions and Differential Mucin Gene Expression in Giardia duodenalis Infection". Am J Pathol.:(2017). 187(11):2486-2498.

18. Hasnain SZ, Wang H, Ghia JE,Haq N, Deng Y,Velcich A,Grencis RK, Thornton DJ, Khan
WI." Mucin gene deficiency in mice impairs host resistance to an enteric parasitic infection", Gastroenterology: (2010)138(5):1763-71.

19. Toma Rasha S, and AL-Hadraawy S. K." Trefoil factor3 (TFF3), Calprotectin (CALP) and (SIgA) as immunological markers in Patients infected with Giardia lamblia Parasite pharm". Sci. and Res. Vol.:(2018) 10(9), 2221-2224.

20. Friedman S, Blumberg RS.’Inflammatory bowel disease". In: Harrison's principles of internal medicine, 17th ed. McGraw Hill, 2008:1886-1899.

21. Salman, Y J, AliCH E and Abdul-Razaq, A.A." Fecal calprotectin among patients infected with some protozoan infections".Int. J. Curr. Microbiol. App. Sci, 2017; 6(6): 3258-3274.

22. Tibble J, Sigthorsson G, Foster R, Sherwood R, Fagerhol M, Bjarnason I. "Faecal calprotectin and faecal occult blood tests in the diagnosis of colorectal carcinoma and adenoma". Gut 2001; 49: 402-8.

23. Striz,I,Trebichavsky I ."Calprotectin-A Pleiotropic Molecule In Acute And Chronic Inflammation". Physiological Research/Academia Scientiarum Bohemoslovaca. (2003). 53 (3): 245-53. 